\title{
A constituição ambígua do político em Staat, Bewegung, Volk de Carl Schmitt
}

\author{
Danilo Vaz-Curado R. M. Costa*
}

recebido: $08 / 2014$

aprovado: $12 / 2014$

\begin{abstract}
Resumo: $O$ presente texto propõe a analisar o conceito do politico em duas obras de Carl Schmitt. As obras utilizadas serão Conceito do Político e Estado, Movimento, Povo. Espera-se poder demonstrar que o politico é um conceito de esfera extrema, não sendo pois definivel. Espera-se também demonstrar que desta comparação resulta o uso ambíguo do conceito político em Carl Schmitt.
\end{abstract}

Palavras-Chave: Político, Movimento, Ambíguo, Schmitt.

Abstract: This paper aims to examine the concept of the political in two works of Carl Schmitt. The works that will be used are 'The Concept of the Political' and 'State, Movement, People'. Expected to be able to demonstrate that the political is a concept of extreme sphere and therefore not definable. It is also hoped that this comparison results demonstrate the ambiguous use of concept the political in Carl Schmitt.

Keywords: Political, Movement, Ambiguous, Schmitt.

\section{Introdução}

O presente trabalho propõe-se a apresentar o conceito de político e as ambiguidades contidas em seu uso a partir das reflexões acerca da unidade política e de sua divisão triádica, tais como expostas no texto Staat, Bewegung, Volk de Carl Schmitt. Para tanto, e com o fito de atingir seu objetivo, o texto se dividirá em quatro momentos.

O primeiro momento do texto reconstruirá a noção do político na obra Conceito do Político, expondo sua estrutura, seu

\footnotetext{
*Universidade Católica de Pernambuco/Brasil.Em@il: danilo@unicap.br. A presente pesquisa contou com o suporte financeiro da Fundação de Amparo à Ciência e Tecnologia do Estado de Pernambuco/FACEPE, através do processo ACE-0045-7.01/14.

Problemata: R. Intern. Fil. v. 5. n. 2 (2014), p. 285-301 e-ISSN 2236-8612 doi:http://dx.doi.org/10.7443/problemata.v5i2.20407
} 
propósito e as suas determinantes conceituais, espera-se neste momento delimitar o padrão ordinário, e usual nos debates sobre o conceito do Político, em Carl Schmitt, preparando as condições para a tematização central a ser desenvolvida no presente texto.

Num segundo momento, o presente paper explicitará como se organiza este mesmo conceito do Político e explicitará a sua constituição como possuindo em sua gênese um movimento triádico, tal como exposta em Estado, Movimento, Povo, buscando determinar sua estrutura, propósito e as suas determinantes conceituais.

Num terceiro momento, se fará o confronto das perspectivas conceituais do Político expostas em Conceito do Político e em Estado, movimento, povo, para no momento subsequente, argumentar em torno de uma ambiguidade do conceito do político exposta em Estado, movimento, povo, sem com isso precisar assumir uma ruptura na ordem dos conceitos no pensamento schmittiano.

\section{O Político em O Conceito do Político}

A primeira questão que se impõe é: porque iniciar um texto acerca da ambiguidade do político na obra $\mathrm{SBW}^{1}$ por outra obra, notadamente $O$ conceito do Politico? A resposta parece extrair-se do próprio desenvolvimento dos conceitos no pensamento schmittiano, pois se em $B P$ o político emerge como consubstancial ao Estado e a crise desta relação é o cerne do ensaio, no contexto geral da produção científica o Político será um tema que não gozará mais de um corpus explicativo até aproximadamente 1969 com a nova edição da Teologia Política.

Há um conjunto de razões que poderiam explicar esta ausência na tematização do tema $O$ político mas admitiremos que tal ausência deve-se, em sua maior parte, pela clareza e maturidade que este tema assume já em $O$ conceito do político ${ }^{2}$, maturidade que deverá se reavaliar quando dos atribulados momentos que antecedem a $2^{\text {a }}$ Grande Guerra.

Carl Schmitt no posfacio de 1932 ao $B P^{3}$ declara que o político é um conceito incomensurável, diferindo dos conceitos usuais da teoria política, em geral, e da ciência política, em especial, aos quais se aplicam métodos quantitativos de 
mensuração de seu valor e potencial de diagnose, por exemplo: participação popular, partido político etc.

Tal caráter não mensurável reside no próprio estatuto da vitalidade do objeto a que ele se refere, pois sendo a vida, em geral, dinâmica e o político uma das dimensões essenciais da vida especificamente humana, seu campo não pode ser delimitado por definições ad extra ${ }^{4}$. Entende-se por ad extra toda definição que apele a um conceito não pertencente à esfera argumentativa em apreço, por exemplo, argumentar acerca do estado a partir de um princípio lúdico, etc.

Para o entendimento do Político, além desta necessária compreensão do campo do político não se pode perder de vista o fenômeno nas suas repetidas re-incursões na história, em suas sempre renovadas constituições. Uma das principais conclusões a que Schmitt chega em suas reflexões introdutórias à delimitação do campo do político no $B P^{5}$ é que tanto o conceito de Estado é coextensível ao do Político como se está face ao destronamento do Estado como detentor do monopólio do político ${ }^{6}$.

Tal constatação coloca-se no plano das configurações históricas da determinação do campo de político como uma condicionante da destituição promovida pelo liberalismo no âmbito do Estado, retirando do ente estatal a primazia e capacidade de aglutinar a dimensão ordenadora do político ${ }^{7}$.

Schmitt identifica que o liberalismo e sua tendência analítica de quantificar a realidade e subsumir o espaço da decisão ao cálculo, a deliberação ao interesse, as questões públicas aos desejos particulares, desarticulou o Político enquanto dimensão do Estado, dispersando o Político na sociedade civil.

Carl Schmitt conclui à luz de sua reflexão acerca da incapacidade do Estado, no momento do liberalismo, em constituir, aglutinar e se o espaço do Político que "O conceito de Estado pressupõe o conceito do político" , mas que a associação entre estatal e político não é mais legítima ${ }^{9}$ porque se o Estado constitui-se como a condição peculiar de um povo que fornece a medida da decisão, ao mesmo tempo a época de Schmitt, como também parece ser o caso da nossa, tais decisões colocaram-se no campo meramente prático-científico de instituição decisória despolitizada, esvaziando a dimensão polêmica do político. 
Esta trajetória de dissociação entre o Político e o Estado inicia-se na perspectiva schmittiana a partir do Estado Absoluto no século XVIII e se consuma com o estado neutro do século XIX e XX. A democracia e o liberalismo aboliram com seus princípios de representatividade, do parlamento, da igualdade, do individualismo, do Estado de direito entre outros a unidade entre o Estado e o Político, ao despolitizar no Estado o âmbito de ação do político ${ }^{10}$, Schmitt entende que se desarticulou a própria relação entre a vida humana $\mathrm{e}$ as formas institucionalizadas de sua realização, entregando-se a ação humana ao campo da tendência, da ação instrumental, e da privatização do mundo da vida.

Com o liberalismo ocorre uma falsa politização das instâncias sociais intermediárias pelo desaparecimento das distinções entre os diversos níveis de estruturação da sociabilidade (v.g. religioso, cultural, econômico, jurídico, científico). Eliminando a distinção que marcava estes metaníveis, o liberalismo termina por apagar a própria distinção Estado $x$ Sociedade, conduzindo a incapacidade de o Estado se colocar como sendo o detentor do monopólio do Político.

A democracia e o liberalismo ao delimitarem as dimensões constitutivas da sociabilidade determinantes do político despolitizando-as, nulidificando seus limites, neutraliza o agonismo que nutria e vivificava as relações entre: Estado e Sociedade, Estado e Político etc. Ao fazê-lo, ao invés de suprimir o político, permitiu que mediante o deslocamento do Estado enquanto lugar do Político, este emergisse em sua forma mais imediatas, tais como estas se mostram na sociedade civil. Ao conduzir o deslocamento do político do Estado para as suas vias intermediárias a dispersão do espaço do político conduziu a sua perda de autonomia. A sociedade civil subsumiu não apenas o espaço do política, mas neutralizou a ação do Estado.

Antes de estabelecermos o critério de distinção do Político, cumpre delimitar o uso da expressão para evitar-se incoerências, pois o Político é o conceito central das reflexões schmittianas até a segunda guerra mundial, inclusive, mesmo que pensado à luz do registro estabelecido em $B P$, sendo apenas após a queda do Nacional-Socialimo substituído pelas noções de Nomos, de Grossraum e de Ordem concreta.

O político por mais paradoxal que tal afirmação possa ser, constitui-se em diversas dimensões ${ }^{11}$, como aquela na qual 
ele tem uma (i) pretensão salvífica, qual seja, a de refazer o tecido conjuntural-espiritual de um povo em geral, e o povo alemão, em específico, em outras palavras, restituir às instituições a unidade política perdida; assim como pode o político assumir uma (ii) dimensão transcendental, por constituir-se como as condição de possibilidade para a estruturação jurídico-política nas sociedades contemporâneas; e, por fim, uma (iii) dimensão técnica, enquanto é o político objeto de estudo de uma ciência específica, a ciência política, entre tantos outros usos possíveis.

Constitui-se, portanto para Schmitt o Político na condição de organização comunitária, de qualquer e todo modo de organização comunitária, que subjaz a esta mesma organização sem subsumir-se aos critérios racionais de sua autocompreensão.

O Político é um conceito de esfera extrema, ou seja, não se permite, nem deixa apreender pelas delimitações conceituais da ciência que o aborda, ele as ultrapassa. Tome-se, por exemplo, o caso do texto Teologia Política. Nela o Político é estudado à luz de sua realização teológica, ou em Estado, movimento, povo, onde ele emerge à luz de sua condicionante realista, todavia, nenhuma destas leituras é condicionante das demais, elas são complementares.

Com este esclarecimento prévio, podemos abordar o modo próprio de delimitação da noção de Político na obra Conceito do Político, relativa à antinomia amigo-inimigo. A primeira pergunta que emerge é o porquê do uso por Schmitt de um critério dualista para circunscrever a noção do político. A resposta com certeza repousa no próprio oponente a que Schmitt se coloca, o liberalismo, e sua capacidade de neutralizar distinguindo e despolitizando todas as dimensões com as quais [o liberalismo] se relaciona.

$\mathrm{O}$ uso do dualismo criteriológico possui o caráter dinâmico de separar e distinguir as esferas a serem estabelecidas pelo seu uso, sem contudo, reduzi-lo a este critério. Tal distinção promovida pelo critério amigo-inimigo é conceitual, mas não definitória, ou seja, permite a sua apreensão conceitual sem precisar encarcerá-lo no limite de uma definição. Assim, tal critério pode se reportar a toda a ação especificamente política sem subsumi-la à um modelo do tipo normativo. Lembrem-se, o político é um conceito de esfera extrema! 
Schmitt, assim se coloca frente a seu critério

\begin{abstract}
A distinção especificamente política a que podem reportar-se as ações e os motivos políticos é a discriminação entre amigo e inimigo. Ela fornece uma determinação conceitual no sentido de um critério, não como uma definição exaustiva ou especificação de conteúdos ${ }^{12}$.
\end{abstract}

Importa acentuar que a presente distinção não se coloca no bojo das claras contraposições entre bem e mau, próprias da moralidade, ou belo e feio, enquanto típicas de um juízo estético, tal contraposição coloca-se como critério e não como juízo valorativo próprio. Schmitt acredita que seu critério possui assim objetividade ${ }^{13}$, por ser capaz de se colocar face a outras diferenciações sem reduzir-se a estas, em suma, ser compreendido como algo independente.

A contraposição amigo-inimigo [Freund-Feind] apenas indica o grau de intensidade numa relação com vistas a um fim associativo, comunitário, e logo, político! A advertência schmittiana é fundamental, pois o inimigo não é, necessariamente, moralmente imoral, esteticamente feio ou economicamente o concorrente.

O inimigo é o estrangeiro [Der Fremde], aquele que nega o que pressupõe meu conceito de Estado, logo, me nega como existencialmente portador e destinatário do Político.

O estrangeiro enquanto inimigo é todo aquele portador do princípio antagônico à minha concretização existencial do político, entendida, claro o pronome possessivo minha, não na primeira pessoa do singular de um sujeito concreto, mas de uma comunidade concreta.

Impõe-se ainda registrar que inimigo é o público, hostis, e nunca inimicus, toda a tensão do conceito reside em polemos, para que não se recai no argumento liberal do inimigo como um concorrente. Inimigo é o que se coloca no máximo antagonismo político, na mais extrema contraposição.

Schmitt, nas palavras de Flickinger, "[...] reconhece a esfera do político como instância última e intransponível da legitimação legal-racional"14 da vida comunitária e é nos termos desta explicitação que ele deve ser entendido. 


\section{O Político em Estado, Movimento, Povo}

Inicialmente deve-se justificar a escolha de texto tão controverso. Por quê? A primeira justificativa reside num certo esquecimento a que ele fora submetido pelos irreparáveis erros cometidos por Schmitt em suas escolhas pessoais; uma segunda justificativa reside no caráter polêmico no qual ele se constitui, delimitando, descrevendo e explicitando de forma imediata, sem tergiversações, o conceito do político que emerge do estado de exceção, no qual se inscreve Carl Schmitt quando da redação do texto; e a terceira justificativa é que a ambigüidade que se argumentará como presente no texto e constitutiva da noção de político é que confere a sua coerência interna no todo da obra schmittiana.

Estado, movimento, povo é um pequeno texto que ordinariamente é associado a um oportunismo schmittiano em face da ascensão do Nacional-Socialismo, que divide-se em quatro momentos: (i) A atual situação constitucional ${ }^{15}$, (ii) a articulação tripartite da unidade política ${ }^{16}$, (ii) a construção bipartite do Estado liberal-democrático e o Estado do funcionalismo público atual ${ }^{17} \mathrm{e}$, por fim, (iv) autoritarismo e homogeneidade de raça como conceitos fundamentais do direito nacional-socialista ${ }^{18}$.

A modo de introdução, deve-se colocar a questão de por quê Schmitt adota a estrutura triádica em Estado, movimento, povo e não o dualismo antinômico de $B P$ como constituinte hermenêutico o Político? Duas hipóteses razoáveis podem ser postas, sendo a primeira relativa ao próprio estado políticoconstitucional do momento gerativo e formativo do texto que mudara brutalmente, saindo de um Estado de direito-liberal para uma conformação de Estado de exceção total, e uma segunda, a esta vinculada é a necessária reconfiguração do político pela entrada de um elemento re-organizador, mediador, na sua estruturação $^{19}$, por substituição ao estado liberal.

Acerca da nova situação constituição da Alemanha enquanto elemento base das reflexões de Schmitt, é preciso sempre assinalar que a ascensão do Nacional Socialismo deu-se pelas vias prescritas pelo positivismo jurídico, o qual encontra na Lei o critério último de legitimidade, em franca oposição as teses schmittianas a época. 
Uma segunda menção deve ser feita ao caráter de novo a que se aludia quando da conformação do Nacional-Socialismo pré-nazismo $^{20}$ enquanto elemento impulsionador das forças enérgicas daquele momento e que podem se traduzir numa frase de Schmitt em Estado, movimento, povo de que "A primazia da liderança política assume a função de uma lei fundamental, positivamente válida, do Estado presente" ${ }^{\text {21 }}$.

Pelo que se depreende que a relação entre NacionalSocialismo e o pensamento schmittiano, ou a tese de que Schmitt fora o ideólogo do nacional-socialismo devem ser melhor conceitualizadas e não apressadamente assumidas como faz, v.g. Zarka ${ }^{22}$.

Este novo é a apropriação do político por uma de suas dimensões constitutivas, dado desconhecido pelo liberalismo que dispersava o político, neutralizando-o. Este dado novo que se apresenta em Estado, movimento, povo se revelará como o ponto de coerência interna da obra schmittiana, qual seja, o caráter existencial do político e sua necessária pressuposição ao jurídico como condição legitimadora.

Note-se que mesmo onde ocorre uma adesão do pensamento schmittiano aos horrores de uma compreensão política de mundo, como aquela do Nacional-Socialismo, não há um caráter oportunista ou um mero adesismo, mas uma crença no Político como dimensão fundamental da existência política.

Em que consiste esta nova estrutura do político e qual a função de seus determinantes Estado, movimento, povo?

Comecemos por seus determinantes, afirmando com Schmittt que há uma primazia do Movimento sobre o Estado e o Povo $^{23}$, sendo aquele o elemento aglutinador que perpassa, lidera-os e estrutura a unidade de sua constituição política.

Schmitt preconiza que eles se conectam e se relacionam de modo transversal, assim como possuem notas diferentes e constituições distintas, há entre eles uma espécie de conformatio oppositorum. Cada palavra - Estado, Movimento, Povo enquanto núcleo delimitador da semântica de sua constituição tem a faculdade de representar tanto a unidade diferenciada e diferenciadora, quanto o todo da unidade política ${ }^{24}$, sem promover a descontinuidade que lhes é constitutiva.

Estão estes elementos, Estado, movimento, povo assim dispostos: 
- O Estado corresponde ao elemento político em sua dimensão estática.

- O movimento efetiva-se como o elemento político em sua dimensão dinâmica.

-O povo por sua vez revela-se como elemento de dimensão apolítica [unpolitische].

Não há propriamente oposição entre eles e disto resulta a ruptura de Schmitt face ao modelo antinômico de Weimar e do dualismo posto em $B P$, porque tal pressuposição implicaria assumir de que o novo (O Nacional Socialismo) deve-se utilizarse do velho (O liberalismo), restaurando os dilaceramentos liberais, relativizando a constituição do Político.

Quanto a este ponto, Schmitt é bem peremptório, afirmando que "O vivo não precisa se legitimar perante o morto, e nem a força em face da fraqueza" ${ }^{25}$. Tal perspectiva parece a primeira vista uma espécie de transposição da violência, sem mais, para a linguagem política, mas, ao contrário Schmitt desejar realçar o indissociável caráter agônico do Político.

Há aqui já os rastros da ambigüidade como estruturadora do Político na obra de Schmitt, pois se, em $B P$, o político era um conceito de esfera extrema não subsumível à uma lógica científico-instrumental, à uma definitio; em Estado, movimento, povo, Schmitt tenta estabelecer uma clausura ao político, negando sua própria origem meta-racional ou pré-racional, não redutível ao discurso lógico-metafísico ou descritivista da ciência ao identificá-lo com o movimento e descrevê-lo com pretensões cientificistas de tipo funcional.

Porém, onde reside a clausura do Político em Estado, movimento povo? A resposta para Schmitt é clara e se coloca na identificação do movimento com o político e na restauração da tese de que o político pressupõe o Estado, já proclamada em $B P$ e implementada em Estado, Movimento, Povo como uma apologia ideológica ao movimento nacional socialista.

Se em $B P$, o Estado é o campo do político, em Estado, movimento, Povo, o politico se localizará no movimento. Há em Estado, movimento, Povo uma determinação espaço-temporal, e uma localização conceitual do político no movimento, quando em $B P$, havia apenas uma espacialização do campo do político, e nunca sua temporalização.

Em razão desta diferença do espaço do político nas obras BP e Staat, Bewegung, Volk é que se pode argumentar num 
sentido da coerência inicial das análises de Schmitt acerca do político nas duas obras, pois o político não é estático, e ao mesmo tempo propor sua ambiguidade.

Nas palavras de Schmitt

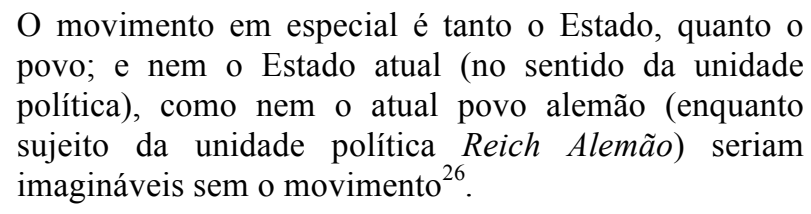

Assim, Schmitt conecta a estruturação do conceito do político em Estado, movimento, povo com sua identificação ao movimento. Onde em $B P$ havia um critério de visualização do político, em Estado, movimento, povo há a própria identificação hipostasiada do Político numa de suas dimensões constitutivas.

Nesta perspectiva desenvolvida por Schmitt, o movimento desempenha uma dimensão lógica de mediação [Vermittlung] entre as dimensões que ficaram em razão da estruturação política-liberal perdidas em seus extremos (o estado e o povo), re-conectando-os.

Assim, o partido, ou, o movimento, é tanto o povo enquanto se constitui pelo pertencimento deste no projeto político daquele, como Estado na medida em que se constitui pelo conjunto dos órgãos e repartições do Estado aglutinadas e reunificadas pelo movimento ${ }^{27}$, que realiza na dimensão técnicoburocrática sua essência política.

Desta forma, o Político perde seu caráter polêmico e sua nova constituição esvazia seu caráter agônico deixando este de ser um conceito de esfera extrema não redutível à um dado da realidade, para se identificar diretamente com a própria realidade, reduzindo-se a um momento constitutivo desta.

Schmitt afirma que "A articulação tripartite, porém, não transparece apenas em todos aqueles casos, nos quais se tenta vencer os becos sem saída do sistema liberal-democrático $[\ldots]^{\prime 28}$, ou seja, a nova constituição do político proposta por Schmitt possui como uma das suas dimensões constitutivas a superação da encruzilhada posta pelo liberalismo de compreender o Estado como Estado de Direito, dissolvendo-o aos moldes normativistas em universais como: direito à educação, direito à liberdade, direito à igualdade, renunciando à sua dimensão político-existencial que preconiza não o direito à 
[...], mas a unidade entre o $\operatorname{Ser}$ (o político) e suas pretensões normativas (o dever-ser).

E, este beco sem saída a que alude Schmitt é o fato de que antes do nacional-socialismo o Estado houvera perdido a primazia e o monopólio sobre o Político, dissolvendo-o, dispersando-o e difundindo-o nas esferas da moral, da economia, do direito, da religião etc. Todavia é o político agora enclausurado num dos vetores através dos quais ele deveria se efetivar, o movimento.

Flickinger aduz que "A valorização do movimento nacional-socialista [por Schmitt] alimenta-se da denúncia de que o sistema democrático-representativo negligenciaria ou até recalcaria o espaço verdadeiro do político, enquanto lugar da luta pública pelo bem comum da comunidade no seu todo"29. Tal assertiva apenas em parte é verídica, pois ela em última instância implicaria o argumento do oportunismo e do caráter patético de Schmitt preconizada por Mehring.

Em Estado, movimento, povo, Schmitt coerente com o exposto em $B P$ recoloca a pressuposição do Estado pelo Político não de modo teórico programático, mas de modo definitivo aduzindo que

O político desloca-se em Estado, Movimento, Povo, do Estado enquanto dimensão que se estruturou pela via liberal de modo estático, para o Movimento enquanto dimensão que emergindo como inimiga do liberalismo, estruturou-se como portadora do dinamismo social e detentora de um tipo de autoridade que dada as circunstâncias da época se legitimava de modo autorreferente.

O movimento enquanto dimensão originária do Político, na concepção de Schmitt promoveria a vivificação política da dimensão estática, dotando-lhe de vida e dinamismo e incluiria nos processos agônicos de efetivação do todo comunitário a dimensão apolítica do povo, alheia à sua dimensão essencial. 
O movimento ao colocar-se entre a apatia do povo e a estagnação do Estado reivindicou para si o espaço do político, enclausurando-o e transferindo para o aparato normativo do Estado o agonismo próprio do movimento, enquanto movimento supraestatal e para-estatal.

Deste modo, a passagem em Schmitt de um critério ou modelo bipolar de compreensão do político, baseado na distinção amigo-inimigo internaliza-se numa tripartição da dimensão do político gerando a ambiguidade neste que é um conceito central na sua obra, o qual doravante passamos a explicitar.

Tal internalização, corresponde a apropriação pelo Nacional-Socialismo do Estado Alemão, e consequentemente do critério e campo do político, conduzindo a internalização da resposta ao modelo liberal proposta em $B P$ como modo legitimador dos processos de esvaziamento do próprio antagonismo político.

E eis que emerge com toda a força o caráter ambíguo do político em Staat, Bewegung, Volk, pois ao internalizar o modelo bipolar dentro de uma estrutura triádica, localizando o político no movimento, Schmitt restituiu o político como ordenador das instituições ao preço de o critério do político do $B P$ tornar-se um instrumento de efetivação do próprio projeto nacional-socialista.

Schmitt torna ambígua sua compreensão do Político em Estado, Movimento, Povo na exata medida em que ao não renunciar ao campo conceitual do Político de BP, mas o localizar como momento interno do Estado Nacional-Socialista, precisa re-estruturar o Político através das novas determinações tais como expostas no movimento, criando um agonismo interno entre a bipolaridade interna ao político estatal e monocromia do movimento.

Onde antes a relação amigo-inimigo descrevia a esfera do político, após o advento do nacional-socialismo, é na relação amigo-inimigo compreendida nos limites do movimento que se descreve o espaço do político, pois segundo Schmitt

O movimento é, em sentido específico, o elemento político da comunidade, o motor dinâmico frente ao elemento estático do aparato público que recorre às normativizações e decisões políticas nelas contidas; é igualmente o garante político da despolitizada autoadministração municipal e sindical ${ }^{31}$.

Problemata: R. Intern. Fil. v. 5. n. 2 (2014), p. 285-301 e-ISSN 2236-8612 


\section{Do caráter ambíguo do político em Schmitt}

Inicialmente cumpre advertir que ambíguo aqui se utiliza no sentido de um conceito que possui um plurivocidade de significados, sendo, portanto, irredutível a uma definição, aprisionamento ou reducionismo cientificista. Portanto, é ambíguo todo conceito, em certa medida, não-definível.

No caso em apreço, a avaliação da ambigüidade no conceito do político em Estado, movimento, povo, pode ser resumida em alguns pontos chaves como: a perda da autonomia do campo do político, a explicitação cientificista de seu objeto, a identificação indevida do todo do fenômeno com um dos modos de seu vir-a-ser, o deslocamento do político para a política, entre outros dados da ambigüidade que aqui poderiam ser ventilados.

Schmitt, em Estado, movimento, povo desloca o campo do político para o campo da política, descrevendo em termos de ação instrumental, estratégica, um conceito que é de base préracional, ou seja, irredutível à uma dimensão empírica ou histórica do seu vir-a-ser.

Ao fazê-lo, Schmitt, caiu na mesma deriva do liberalismo, todavia em sentido oposto, qual seja: se o liberalismo despersonaliza, neutraliza e despolitiza o espaço autônomo do político pelo recurso à impessoalidade da ordem normativa e a identificação do Estado enquanto destinatário do político com a frieza do dever-ser legal, Schmitt, em sentido inverso estrutura o político num hiperrealismo modal, no qual o movimento exclui categorialmente os demais âmbitos (Estado e povo) enquanto dimensões portadoras do político.

Neste viés de identificar o Político ao movimento, Schmitt suprimiu a autonomia do político por identificá-lo diretamente e sem mediações com o movimento, e este com o partido nacional-socialista, retirando todo o potencial de diagnose outrora exposto em $B P$, e fazendo do político um conceito descritivista, empírico.

Ao descrever em termos empíricos a fenomenalização do Político com dados e descrições funcionais como a regulação, a estruturação e mesmo a dinâmica do movimento, Schmitt incluiu na perda de autonomia do político um novo déficit 
referente à tentativa de cientificização de seu objeto, do enclausuramento seguiu-se a sua normatvização.

Neste processo de cientificização comete Schmitt um segundo equívoco, aquele de tomar a parte pelo todo, num claro argumento pars pro totum posto que universalizou indevidamente um dado concreto.

Todavia, tais identificações da proposta de Schmitt em Estado, movimento, povo não teriam o efeito inverso do defendido neste texto, qual seja, retirariam o caráter ambíguo do político?

Defende-se que não exatamente, porque, argumenta-se no presente texto que há uma continuidade entre $B P$ e Estado, movimento, povo, no sentido de que o critério do político exposto em BP fora internalizado em Estado, movimento, povo.

Deste modo, o movimento quando passou a ser o portador da verdade acerca da dimensão amigo-inimigo, torna o conceito do Político um conceito ambíguo, pois portador de duas dimensões hermenêuticas opostas, aquela do Político enquanto político, própria de $B P$, e esta outra do Político enquanto Política, própria a Staat, Bewegung, Volk.

Neste contexto interpretativo, o realismo moderado de Carl Schmitt exposto em $B P$ sucumbe face ao hiperrealismo de Estado, movimento, povo, e o político revela em toda a sua perplexidade a incapacidade de seu aprisionamento, tornando-se Schmitt refém de sua própria obra, pois ao tentar tornar visível o invisível e pensando descrever a fenomenalização de seu conceito, descrevera em verdade um Simulacro!

\section{Referências bibliográficas}

BAUME, Sandrine. Carl Schmitt, penseur e l'État: Gènese d'une doctrine. Paris: Press Sciences PO, 2008.

Le talon d'Achille de la distinction schmittiene du politique. in GRANGÉ, Ninon (org.). Carl Schmitt: Nomos, Droit et conflit dans le relations internationals. Rennes: Press Universitaires de Rennes, 2013.

FERREIRA, Bernardo. O risco do Político. Belo Horizonte: UFMG/IUPERJ, 2004.

FLICKINGER, Hans-Georg. Movimentos sociais e a construção do Político. Civitas - Revista de Ciências Sociais. v. 4, n. 1, 
jan.-jun. 2004.

HOOKER, William. Carl Schmitt's International Thought Order and Orientation. New York: Cambridge University Press, 2009

MEHRING, Reinhard. Pathetisches Denken: Carl Schmitts Denkweg am Leitfaden Hegels: katholische Grundstellung und antimarxistische Hegelstrategie. Berlim: Duncker \& Humblot, 1989.

- Carl Schmitt, Der Begriff des Politischen: ein kooperativer Kommentar. Berlim: Akademie Verlag, 2003

SCHMITT, Carl. Staat, Bewegung, Volk: die Dreigliederung der politischen Einheit. Hamburg: Hanseatische Verlagsanstalt, 1933.

. Der Begriff des Politischen. Berlim: Duncker \& Humblot, 2002. Siebente Auflage. . O Conceito do político. Trad. Álvaro Valls. Petrópolis: Vozes, 1992.

. Der nomos der Erde - im Völkerrecht des Jus Publicum Europaeum. Berlim: Duncker \& Humblot, 1974. Zweite Auflage.

ZARKA, Yves Charles. Un détail nazi dans la pensée de Carl Schmitt. Paris: PUF, 2005.

\footnotetext{
Notas

${ }^{1}$ Staat, Bewegung, Volk [Estado, movimento, povo].

${ }^{2}$ Acerca desta questão é útil o estudo de Sandrine Baume Carl Schmitt penseur de l'Etat.

${ }^{3}$ Doravante todas as vezes em que se fizer menção à obra Conceito do Político se utilizará a sigla BP.

4 Carl Schmitt. Der Begriff des Politischen. p. 9 [trad.31] „Das Beziehungsfeld des Politischen ändert sich fortwährend, je nach den Kräften und Mächten, die sich miteinander verbinden oder voneinander trennen, um sich zu behaupten".

${ }^{5}$ Der Begriff des Politischen [O Conceito do Político].

${ }^{6}$ Carl Schmitt. Der Begriff des Politischen. p.10 [trad.32] „Der Staat als das Modell der politischen Einheit, der Staat als der Träger des erstaunlichsten aller Monopole, nämlich des Monopols der politischen Entscheidung, dieses Glanzstück europäischer Form und occidentalen Rationalismus, wird entthront".

${ }^{7}$ Para uma visão ampla deste tema O risco do político, Bernardo Ferreira.
} 
${ }^{8}$ Carl Schmitt. Der Begriff des Politischen. p.13 [trad.35] ,So lautet gleich der erste Satz: "Der Begriff des Staates setzt den Begriff des Politischen voraus".

${ }^{9}$ Carl Schmitt. Der Begriff des Politischen. p.24 [trad. 47] „Dagegen wird die Gleichung Staatlich = Politisch in demselben Masse unrichtig und irreführend, in welchem Staat und Gesellschaft sich gegenseitig durchdringen $[\ldots .$.$] ".$

${ }^{10}$ A perspectiva aqui desenvolvida coloca-se em franca oposição àquela de Sandrine Baume in Le talon d'Achille de la distinction schmittiene Du politique, onde há uma hipostasiação do político como localizado no Estado numa franca desvalorização de indicativos explícitos de Carl Schmitt contra esta localização.

${ }^{11}$ Aqui, segue-se, em geral, as reflexões de H.G. Flickinger em Movimentos sociais e a construção do Político, $p .13$ e segs.

${ }^{12}$ Carl Schmitt. Der Begriff des Politischen. p.26 [trad. 51] „,Die spezifisch politische Unterscheidung, auf welche sich die politischen Handlungen und Motive zurückführen lassen, ist die Unterscheidung von Freund und Feind. Sie gibt eine Begriffsbestimmung im Sinne eines Kriteriums, nicht als erschöpfende Definition oder Inhaltsangabe".

13 Carl Schmitt. Der Begriff des Politischen. p.28 [trad. 53] „Die seinsmäßige Sachlichkeit und Selbständigkeit des Politischen zeigt sich schon in dieser Möglichkeit, einen derartig spezifischen Gegensatz wie FreundFeind von anderen Unterscheidungen zu trennen und als etwas Selbständiges zu begreifen

${ }^{14}$ H.G. Flickinger em Movimentos sociais e a construção do Político, p. 16.

${ }^{15}$ Carl Schmitt, Staat, Bewegung, Volk, pp.5-10

${ }^{16}$ Carl Schmitt, Staat, Bewegung, Volk, pp.11-22

${ }^{17}$ Carl Schmitt, Staat, Bewegung, Volk, pp.22-32

${ }^{18}$ Carl Schmitt, Staat, Bewegung, Volk, pp.32-46

${ }^{19}$ Não nos filiaremos aqui as teses que veem em Schmitt um hegeliano patético como Reinhard Mehring, tal como se a opção triádica esconde-se uma velha tese hegeliana exposta já em seu livro Órbita dos Planetas de que "Quadratum est Lex naturae, triangulum, mentis" o quadrado é a lei da natureza e o triângulo a lei do Espirito. De modo que a estrutura triádica corresponderia à próprio lei do Espirito, constitutiva do mundo.

20 Designo de pré-nazismo a ascensão do nacional-socialismo até transmutação do estado total em estado racista e dos primeiros decretos violadores de direitos de primeira ordem como liberdade, vida, propriedade, opinião etc., em suam, direitos liberais.

${ }^{21}$ Carl Schmitt. Staat, Bewegung, Volk. p. 10

${ }^{22}$ ZARKA, Yves Charles. Un détail nazi dans la pensée de Carl Schmitt. Paris: PUF, 2005.

${ }^{23}$ Carl Schmitt. Staat, Bewegung, Volk. p. 12.

${ }^{24}$ Carl Schmitt. Staat, Bewegung, Volk. p. 12. „Jedes einzelne der drei Worte Staat, Bewegung, Volk

kann für das Ganze der politischen Einheit gebraucht werden. Es bezeichnet baer gleichzeitig auch eine besondere Seite und ein spezifiches Element dieses Ganzen." 
${ }^{25}$ Carl Schmitt. Staat, Bewegung, Volk. p. 8. ,, Das Lebendige kann sich nicht am Toten und die Kraft braucht sich nicht an der Kraftlosigkeit zu legitimieren “

${ }^{26}$ Carl Schmitt. Staat, Bewegung, Volk. p. 12.

${ }^{27}$ Aqui impõe-se rememorar que o Nacional-Socialismo instituiu a supressão da pluralidade partidária, instituindo o regime do partido único.

${ }^{28}$ Carl Schmitt. Staat, Bewegung, Volk. p. 13.

${ }^{29}$ H.G. Flickinger em Movimentos sociais e a construção do Político, p. 19.

${ }^{30}$ No original: „Heute kann das Politische nicht mehr vom Staate her, sondern muss der Staat vom Politische her bestimmt werden ".

${ }^{31}$ Carl Schmitt. Staat, Bewegung, Volk. p. 17. 